\title{
Comparative Study of Low Doses of Intrathecal Bupivacaine Admixed With Fentanyl Citrate in Caesarean Section Deliveries
}

\author{
${ }^{1}$ Dr. Khaidem Surjit Meetei, ${ }^{2}$ Dr. Ashem Jack Meitei", \\ ${ }^{3}$ Dr. Tikendrajit Ningombam, ${ }^{4}$ Dr. Markitbok Ksanieng, \\ ${ }^{5}$ Dr. Kh. Maniram Singh, ${ }^{6}$ Dr. N. Anita Devi \\ ${ }^{1}$ Junior Resident ${ }^{2}$ Assistant Professor, ${ }^{3-4}$ Junior Resident, ${ }^{5}$ Professor, ${ }^{6}$ Associat Professor \\ Department of Anaesthesiology and Critical Care, Regional Institute of Medical Sciences, Imphal-795004, \\ Manipur, India.
}

\begin{abstract}
Introduction: Spinal anaesthesia using hyperbaric bupivacaine is the technique of choice for caesarean section. Use of higher dose of local anaesthetics can cause haemodynamic instability, maternal and neonatal side effects. We hypothesized that use of lower dose of bupivacaine with fentanyl will improve the quality of analgesia and minimize the complications. Aim is to compare the haemodynamics and duration of analgesia using different lower doses of hyperbaric bupivacaine admixed with fentanyl citrate $12.5 \mathrm{mcg}$.

Methods: Seventy five parturients, scheduled for elective caesarean section were randomly allocated into three groups. Group B $(n=25)$ received bupivacaine $10 \mathrm{mg}(2 \mathrm{ml})$, group BF1 $(n=25)$ received bupivacaine $7.5 \mathrm{mg}$ and fentanyl $12.5 \mathrm{mcg}$ plus NS (to make $2 \mathrm{ml}$ ), group BF2 $(n=25)$ received bupivacaine $5 \mathrm{mg}$ and fentanyl $12.5 \mathrm{mcg}$ plus NS (to make 2ml). Maternal haemodynamics, sensory and motor block, duration of analgesia and the apgar score of the newborn were compared between the groups.

Results: The time required for sensory block was significantly fastest in group BF1(p<0.001). The haemodynamic trend was significantly different in $4^{\text {th }}, 6^{\text {th }}$ and $20^{\text {th }}$ minute of intraoperative period and statistically significant but clinically not significant among the groups. Duration of analgesia was significantly longest $(116.72 \pm 18.80)$ in group BF1 $p<0.001$. Analgesic supplement was maximum in group BF2 (10\%) followed by group BF1 (4\%), group B (0\%) respectively. The analgesic quality was excellent in group BF1 (76\%) followed by group B (64\%), group BF2 (44\%).
\end{abstract}

Conclusion: Bupivacaine $7.5 \mathrm{mg}$ admixed with fentanyl $12.5 \mathrm{mcg}$ is a better option to produce haemodynamically stable and prolonged duration of analgesia for caesarean section.

Key Words: Caesarean section, fentanyl, hyperbaric bupivacaine, low dose, spinal anaesthesia.

\section{Introduction}

Spinal anaesthesia (SA) with bupivacaine has been widely used for caesarean section (CS) deliveries because of multiple advantages. ${ }^{1}$ Bupivacaine causes many undesirable effects like hypotension, bradycardia, shivering, nausea, vomiting etc. However, these effects are dose dependent and can be reduced by using lower dose of bupivacaine with adjuvant. Several adjuvant like morphine, butorphenol, ketamine, alfentanyl, sufentanyl have been exhaustively studied in the population undergoing CS delivery with many side effects. ${ }^{(2-7)}$ Considering the previous studies and results, intrathecal bupivacaine with fentanyl proves most suited combination of SA. ${ }^{(8)}$ Addition of fentanyl to intrathecal bupivacaine reduces the incidence of haemodynamic instabilities and requirement of anaesthetic doses. It is a preferred adjuvant in spinal anaesthesia because of its rapid onset and short duration of action with lesser incidence of respiratory depression. ${ }^{(9)}$ Because of its synergistic effect, it improves intra-operative analgesia and increases duration of post operative analgesia with negligible incidence of pruritus, shivering or respiratory depression. However this intrathecal bupivacaine and fentanyl combination is not always free from the undesired adversities or toxicities of cardiovascular system and central nervous system on both maternal and neonatal due to unwanted cephalad extension of blockade. Several studies in an attempt to prevent spinal induced hypotension, including low dose bupivacaine in combination of fentanyl are being conducted. There is report where fentanyl addition to bupivacaine does not cause any change in the sedation. Further, negligible incidences of pruritus, shivering or respiratory depression were observed.

Hence we conducted the present study to evaluate the lowest effective dose of intrathecal bupivacaine admixed with safe dose of fentanyl citrate in CS delivery without any untoward effects to mother and newborns against the standard bupivacaine alone as control. 


\section{Materials And Methods}

After obtaining institutional ethical committee approval and written informed consent from all the patients. This study was conducted during 2014 to 2016 as a prospective randomized double blinded controlled study at a tertiary teaching hospital at Imphal on 75 patients of ASA I and II, aged between 18 and 38 years of full term singleton pregnant women undergoing elective CS delivery. Patients with severe anaemia, pregnancy induced hypertension (PIH), placenta previa, foetal distress, other systemic diseases, contraindication to neuraxial block, any other medications, extreme of height and weights were excluded from the study.

One day before the surgery, pre anaesthetic check up was done and assuming found fit for surgery, all the patients were premedicated at night with tablet pantoprazol $40 \mathrm{mg}$ and tablet alprazolam $0.5 \mathrm{mg}$ orally, thereafter kept overnight fasting. On arrival at operation theatre, intravenous access was secured with $18 \mathrm{G}$ cannula and ringers lactate infusion was started at $15 \mathrm{ml} / \mathrm{kg}, 15$ minutes before SA. Pre medication was done with injection ranitidine $50 \mathrm{mg}$ iv and injection metoclopramde $10 \mathrm{mg}$ iv. Standard monitors were applied and baseline values were recorded.

Using computer generated code; patients were divided into three groups of 25 patients each: group (B) received bupivacaine $2 \mathrm{ml}$, group (BF1) received bupivacaine $1.5 \mathrm{ml}+12.5 \mathrm{mcg}$ of fentanyl+NS to make volume of $2 \mathrm{ml}$, group (BF2) received bupivacaine $1 \mathrm{ml}+12.5 \mathrm{mcg}$ of fentanyl+NS to make a volume of $2 \mathrm{ml}$. Under aseptic precaution, SA was performed at L3-4 intervertebral space using 25G Quincke needle and either of the study drugs was injected intrathecally in double blind fashion.

Heart rate (HR), systolic blood pressure (SBP), diastolic blood pressure (DBP), mean arterial pressure (MAP) and oxygen saturation (SPO2) were recorded every 2 minutes for the first 10 minutes followed by every 5 minutes till $30^{\text {th }}$ minutes then 15 minutes till the end of surgery.

Sensory level of block was assessed bilaterally by pinprick method along the mid-clavicular line and assessed every 30 seconds till complete loss of cutaneous sensation at T8-T6 at which point surgery was started, then every 2 minute until the highest level has been stabilized for four consecutive tests. Once the peak sensory block level had attained no further sensory check was done. The incidence of adverse effects, such as nausea, vomiting, shivering, pruritus, respiratory depression, sedation, hypotension and bradycardia were recorded.

Motor blockade was assessed (time from the injection of drug in subarachnoid space till the patient was unable to raise the extended legs) by Modified Bromage scale. ${ }^{10}$

Score

Criteria

1. $\quad$ Complete block (unable to move feet or knees)

2. $\quad$ Almost complete block (able to move feet only)

3. $\quad$ Partial block (just able to move knees)

4. $\quad$ Detectable weakness of hip flexion while supine (full flexion of knees)

5. No detectable weakness of hip flexion while supine

6. Able to perform partial knee bend

Fall in SBP $>30 \%$ of baseline or $<95 \mathrm{mmHg}$ was considered hypotension and treated with Inj Ringer's lactate (200mL bolus) and/or Inj. Mephentermine $3 \mathrm{mg}$ intravenous as needed. Pulse rate $<50$ beats per min was considered Bradycardia and treated with inj Atropine. Respiratory depression was defined as respiratory rate less than 10 per min to be treated with inj. Naloxone.

An intra and post operative pain assessment was done using pain grading as fair, poor, good and excellent. Foetal outcome was assessed by apgar score at 1 and 5 minutes. Side effects such as hypotension, bradycardia, respiratory depression, nausea, vomiting, pruritus, shivering and sedation were noted till the end of surgery. Duration of post operative analgesia was taken as time from the end of surgery up to the patient's first analgesia requirement. Rescue analgesia (intra-operative) was provided with inj Ketamine Sulfate 10mg intravenously or Inj Pentazocin 15mg and Midazolam $1.5 \mathrm{mg}$ slow intravenously.

Statistical Analysis: Based on a study, ${ }^{11}$ a sample size of 22 in each group was determined with an alpha value of 0.05 and a power of 0.95 and rounded to 25 patients in each group. The data were tabulated and analysed by the software SPSS for windows version 20.0. Tables and figures were drawn using Microsoft word and excel. Numerical /continuous variables were presented as Mean \pm SD (standard deviation) and for qualitative/categorical variables were again described as number of cases and percentages. The three means for each parameter were compared by ANOVA test (F-test) and for multiple comparisons of means Post Hoc Tests of Bonferroni was advocated whenever applicable. For categorical variables, the information was exhibited in terms of number of cases along with percentages and $\chi^{2}$-test was applied if data permit. The $\mathrm{p}$ value of $<0.05$ was considered statistically significant. 


\section{Results}

The demographic profiles (age, weight and height) of the three groups were comparable and found statistically not significant Table 1 . Figure-1 shows the comparison of Mean \pm SD of heart rate at different stages of pre and intra operative period amongst the three groups were found statistically not significant $(\mathrm{P}>0.05)$. Table -2 shows the comparison pattern of mean haemodynamic changes among the three study groups .The mean systolic blood pressure in Group B, Group BF1 and Group BF2 over the stages starting from pre-operative to 75th minute of intra-operative and the variation of means were found to be statistically significant only at $4^{\text {th }}, 6^{\text {th }}$ and $20^{\text {th }}$ minutes $(\mathrm{P}<0.05)$. However mean DBP and MAP were statistically significant only at $4^{\text {th }}$ and $6^{\text {th }}(\mathrm{P}<0.05)$

The time required for the onset of sensory block to reach T6 was fastest in group BF1, followed by group B and group BF2. The mean difference among the three groups was highly significant $(\mathrm{p}<0.001)$, Table- 3 . There was no failed cases in all the groups. The duration of analgesia was highest in group BF1 and lowest in $\mathrm{BF} 2$. And the mean variation of the three groups was highly significant $(\mathrm{P}=0.008)$. There was no significant difference in APGAR score $(\mathrm{P}>0.05)$ Table-4. Table-5 shows no analgesic supplement was required in group $\mathrm{B}$, whereas $1 / 25$ patient in group $\mathrm{BF} 1$ and $2 / 25$ patients in group BF2 were given pentazocine and $3 / 25$ patients in group $\mathrm{BF} 2$ received ketamine. There was highest percentage $(76 \%)$ of analgesic quality (excellent) in group $\mathrm{BF} 1$, followed by group B (64\%) and group BF2 (44\%) respectively. On contrary both group B and group BF2 had similar percentage (24\%) of good, followed by group BF1(20\%). There was no case of poor in group BF1 whereas Group B had one. Group BF2 had highest percentage (24.0\%) of poor score. In group B and BF2 had two cases each having fair analgesic quality against one case in group BF1. Incidence of nausea and vomiting were absent in group BF1 and group BF2 however $3 / 25$ patients of nausea and 2/25 patients of vomiting were evidenced in group $\mathrm{B}$.

\section{Discussion}

This study was carried out to find out whether the average bupivacaine dose of 6-12.5 mg intrathecal for caesarean section can still be reduced to less than $6 \mathrm{mg}$. It was also to check whether the reduction in dose of intrathecal fentanyl can be possible less than the average 15-25 mcg in previous study. We also tried to keep the level intrathecal injection at the lower site at L3-4 intervertebral space to avoid accentuation of hemodynamic responses. In this study we compared the effectiveness of the three drug doses to give adequate surgical anesthesia for lower caesarean section delivery. Two drug doses group BF1 $(0.5 \%$ bupivacaine $7.5 \mathrm{mg}+$ fentanyl $12.5 \mathrm{mcg}$ ) \& group BF2 (bupivacaine $5 \mathrm{mg}+$ fentanyl $12.5 \mathrm{mcg}$ ) were compared with the standard $10 \mathrm{mg} 0.5 \%$ bupivacaine (heavy). In our result, there was a wide variation of intraoperative maternal HR in all the groups. Though none of the difference was found to be significant. No case of bradycardia requiring injection atropine was observed during intraoperative period in the study.

It has been observed that the trend of fall in systolic blood pressure was significantly different in $4^{\text {th }}, 6^{\text {th }}$ and $20^{\text {th }}$ minute of intraoperative period. It is in congruence with the earlier studies. ${ }^{11-13}$ There was decrease in all the systolic, diastolic and mean arterial pressure following intrathecal injection. However, the decrements in blood pressures were not significant $(\mathrm{P}>0.05)$ amongst the three groups except in the $4^{\text {th }}$ and $6^{\text {th }}$ minutes. The fall was greatest in group B (mean SBP 103.56 \pm 17.12 ), followed by group BF2 (mean SBP 106.12 \pm 16.15 ) and least in group BF1 (mean SBP 115.72 \pm 17.22 ). The diastolic blood pressure also had similar trend of reduction at $4^{\text {th }}$ and $6^{\text {th }}$ minutes intra-operative. Here too, the lowest mean diastolic reading belonged to group-B $(60.16 \pm 14.22)$ followed by group-BF2 $(63.64 \pm 14.46)$ and group-BF1 $(70.96 \pm 14.39)$ respectively. A p-value of 0.030 and 0.025 in both the $4^{\text {th }}$ and $6^{\text {th }}$ minutes reading further asserted the significant differences amongst the three groups. Similar pattern of decrease was also visible in MAP too. Further in the post-hoc analysis this fall in blood pressure was significant in group B and group BF1 but insignificant between group BF1 and group $\mathrm{BF} 2$. In the study by Jaishree Bogra et.al ${ }^{13}$ the decrease in blood pressure was more with increasing dose of bupivacaine, this was in congruence with our present result. K. Jain et.al ${ }^{14}$ also found that addition of $10 \mu \mathrm{g}$ of fentanyl to $7.5 \mathrm{mg}$ of intrathecal bupivacaine could significantly differ the fall in MAP from $7.5 \mathrm{mg}$ alone bupivacaine.

Himabindu G.V. et.al found that addition of $25 \mu \mathrm{g}$ fentanyl to $7.5 \mathrm{mg}$ of hyperbaric bupivacaine could significantly increase the rate of onset of sensory block than $10 \mathrm{mg}$ bupivacaine alone. The results of our study have shown that onset to peak of sensory block (loss of pin prick sensation) to T6 (Table-3) following intrathecal injection was faster in the group BF1 $(218 \pm 49.20 \mathrm{sec})$. Onset of sensory block was slower in group $\mathrm{BF} 2(357.83 \pm 119.35 \mathrm{sec})$ which is still slower than the control group B $(323.04 \pm 81.22)$. Bogra J. et. al ${ }^{15}$ found the similar result of faster sensory onset with increasing bupivacaine alone doses < combination groups with fentanyl. Dhumal P. R. et.al ${ }^{16}$ and Sheikh F. et.al ${ }^{11}$ also found the faster onset of the sensory block in fentanyl combination groups than their bupivacaine alone counterparts. The highest peak sensory block level was not different in group B and group BF1 (highest T2- 4\% prevalence) but none of the group BF2 could reach the T2 level. The prevalence of lowest block level (T8) attained in group B \& BF1 were same (4\%). The 
highest level attained in group BF2 was T4. Rao.V et.al ${ }^{17}$ in their study found that $6 \mathrm{mg}$ of bupivacaine with 25 $\mu \mathrm{g}$ fentanyl was effective for cesarean section delivery and could attained T4 dermatome block level in $40 \%$ of cases. But in our study the maximum sensory block level was T4. It is in congruence with our present study. Gupta A et.al ${ }^{18}$ during spinal anesthesia for ambulatory inguinal hernia studied the effectiveness of $6 \mathrm{mg} \& 7.5$ $\mathrm{mg}$ hyperbaric bupivacaine admixed with $25 \mu \mathrm{g}$ fentanyl. They found greater number of patients in $6 \mathrm{mg}$ group required supplementary analgesics intra-operatively. Most of the earlier studies ${ }^{2,3,14,19,20}$ were conducted in higher doses of bupivacaine $(\geq 7 \mathrm{mg})$ and fentanyl. Goel $\mathrm{S}$ et.al ${ }^{21}$ conducted a study in 45 adult males undergoing day care urological procedure with $5 \mathrm{mg}$ hyperbaric bupivacaine plus varying doses of fentanyl 7.5/ $10 / 12.5 \mu \mathrm{g}$. Fentanyl $7.5 \mu \mathrm{g}$ with bupivacaine $5 \mathrm{mg}$ had a significantly higher (four out of 15 ) block failure rate. Ben-David B et.al ${ }^{8}$ in their study, however, could complete the surgical anesthesia with $4 \mathrm{mg}$ bupivacaine (minidose) plus $20 \mu \mathrm{g}$ fentanyl: a much lower dose. This might be due to the lower dermatomal level of surgical field in their study. In our study, there was no case of block failure, which was in agreement with previous studies. But in $20 \%$ of the cases in Group-BF2 required additional analgesic supplementation during surgery which indicated the poorer adequacy of surgical anesthesia in Group-BF2. However, in a study by Dhumal P.R et.al ${ }^{16} 5 \mathrm{mg}$ bupivacaine with $25 \mu \mathrm{g}$ fentanyl was found to be effective and superior to bupivacaine $7.5 \mathrm{mg}$ alone. The difference in the fentanyl dose might be the reason for less failure rate in their study. From this we could infer that bupivacaine $5 \mathrm{mg}$ could be effective for LSCS if the fentanyl dose be increased $>12.5 \mu \mathrm{g}$. Our study found $20 \%$ cases of nausea and vomiting (table-9) in the Group B whereas; there were no cases in Group BF1 \& $\mathrm{BF} 2$. The increased incidence of nausea and vomiting was found mostly in bupivacaine alone groups in various studies ${ }^{11,13,16}$. Most of the events of nausea or vomiting were found to be in relation to hypotensive episodes. Bupivacaine 10mg was adequate for intraoperative analgesia. But one case in Group BF1 needed analgesic call during intraoperative period. Supplementary analgesia requirement was higher in Group-BF2 (20\%). Similar results were also observed in Gupta A.et.al. ${ }^{18}$ Unlike previous studies in which higher doses of fentanyl were used, in our study there were no cases of pruritus, respiratory depression. The highest mean duration of analgesia was witnessed in group-BF1 $(116.72 \pm 18.80 \mathrm{~min})$ followed by group-BF2 $(98.91 \pm 17.38 \mathrm{~min})$ and lowest in group-B $(105.24 \pm 22.09 \mathrm{~min})$. Again insignificant $\mathrm{P}$ - value i.e., $\mathrm{P}=0.008$ indicates that the variation is very highly significant statistically. Bogra J et.al ${ }^{15}$ and Dhumal P.R et.al ${ }^{16}$ had also observed the similar result of synergistic actions of opioids with local anaesthetics. However, the $1^{\text {st }}$ min and $5^{\text {th }}$ min APGAR score were not different significantly in all the groups (table-4). In fact the intrathecal fentanyl was found to have better neonatal outcome than general anesthesia. ${ }^{12,22}$ The table-5 shows percentage of analgesic quality viz., highest excellent $(76.0 \%)$ was found to exist in group-BF1, followed by group-B (64.0) and group-BF2 (44\%) respectively. On the contrary group-BF2 \& B had highest number of good (24\%), followed by group-BF1 $(20 \%)$. There was no case of poor in group-BF1 and 2 cases (8\%) of fair in group-BF2.

\section{Conclusion}

From this study it could be concluded that use of intrathecal bupivacaine (heavy) $7.5 \mathrm{mg}$ with $12.5 \mu \mathrm{g}$ fentanyl could still be a better option than the standard 10-12.5mg bupivacaine alone regime with improved haemodynamic stability, quality of anaesthesia and better post operative analgesia without significant side effects to neonatal outcome. Further reduction in dose of bupivacaine to $5 \mathrm{mg}$ may be working with $12.5 \mu \mathrm{g}$ fentanyl for cesarean delivery but may require additional analgesia supplementation intra-operatively.

\section{References}

[1]. Hawkins JL, Koonin LM, Palmer SK, Gibbs CP. Anesthesia related deaths during obstetric delivery in the united states, 1997-1990. Anesthesiology, 1997;86:277-284.

[2]. Shrestha SN, Bhattarai B, Shah R, comparative study of hyperbaric bupivacaine plus ketamine vs. bupivacaine plus fentanyl for spinal anaesthesia during caesarean section, Kathmandu University Medical Journal, 2013;11 (44 ):287-291.

[3]. Singh I, Gupta M, Mahawar B, Gupta A, comparison of effect of intrathecal sufentanil-bupivacaine and fentanyl-bupivacaine combination on postoperative analgesia, Indian Journal of Anaesthesia,2008; 52 (3):301-304.

[4]. Kumar B, Williams A, Liddle D, Verghese M, comparison of intrathecal bupivacaine-fentanyl and bupivacaine-butorphanol mixtures for lower limb orthopaedic procedures, Anaesthesia, 2011; 5(2):190-195.

[5]. Cowan C. M., Kendall J. B., Barclay P. M., Wilkes R. G., comparison of intrathecal fentanyl and diamorphine in addition to bupivacaine for caesarean section under spinal anaesthesia, British Journal of Anaesthesia, 2002; 89 (3): 452-58.

[6]. Kim S. Y., Cho1 J. E., Hongl J. Y., Koo1 B. N., Kim J. M., Kil H. K., comparison of intrathecal fentanyl and sufentanil in low-dose dilute bupivacaine spinal anaesthesia for transurethral prostatectomy, British Journal of Anaesthesia, 2009; 103 (5): 750-754.

[7]. Seewal R, Shende D, Kashyap L, Mohan V, effect of addition of various doses of fentanyl intrathecally to $0.5 \%$ hyperbaric bupivacaine on perioperative analgesia and subarachnoid block characteristics in lower abdominal surgery: a dose response study, Reg Anesth Pain Med, 2007 Jan-Feb;32(1):20-26.

[8]. Ben David B, Miller G, Gavriel R, Gurevitch A. Low dose bupivacaine fentanyl spinal anesthesia for caesarean delivery. Regional Anesthesia and Pain Medicine, 2000;25(3):235-239

[9]. Hunt CO, Naulty JS, Bader AM, Hauch MA, Vartikar JV, Datta S, Hertwig LM, Ostheimer GW: Perioperative analgesia with subarachnoid fentanyl-bupivacaine for cesarean delivery. Anaesthesiology, 1989; 71(4):274-278

[10]. Bromage PR. Philadelphia: WB Saunders; 1978: 144 
[11]. Sheikh F, Ahmed M, Ommid M, Gurcoo S, Shakoor N, Nazir S, et al. Comparative evaluation of low dose hyperbaric bupivacaine with or without fentanyl in spinal anaesthesia for caesarean section in patients with pregnancy induced hypertension . Int Journal of Anaesthesiology; 2012; 30(4):14436.

[12]. Ahuja V, Jain K, Ghai B, Kaur J, Datta S, . Best neonatal outcome following emergency ceasarean delivery in non assuring fetal heart rate: General or a low-dose spinal anaesthesia Journal of Obstetric Anaesthesia and Critical care. 2011 (Jul-Dec); 1 (2):67-72.

[13]. Sivevski A. Spinal Anaesthesia For Cesarean Section With Reduced Dose Of Intrathecal Bupivacaine Plus Fentanyl. Sec. Biol. Med. Sci; 2006; MASA- XXVII; 2: 225-236.

[14]. Jain K, Grover VK, Mahajan R, Batra, . Effect of varying doses of fentanyl with low dose spinal bupivacaine for caesarean delivery in patients with pregnancy induced hypertension Int J Obstet Aneth 2004 Oct;13(4):215-20.

[15]. Bogra J, Arora N, Srivastava P,. Synergistic effect of intrathecal fentanyl and bupivacaine in spinal anesthesia for cesarean section. BMC Anesthesiology; May 2005: 5:5

[16]. Dhumal P.R., Kolhe E.P, Gunjal V.B., Kurhekar V.A, Synergistic effect of intrathecal fentanyl and bupivacaine combination for caesarean section. Int J Pharm Biomed Res 2013; 4(1): 50-56.

[17]. Rao V, Annavarapu. M.D, Kumar V, Songa M.D, Sravanthi K.A, Evaluation of effective low dose bupivacaine with fentanyl in spinal anaesthesia for lower segment caesarean section surgeries. IOSR Journal of Pharmacy and Biological Sciences (IOSR-JPBS) Mar -Apr. 2015; Volume 10; Issue 2 Ver. II ; PP 01-06.

[18]. Gupta A, Axelsson K, Thorn SE, Matthiessen P, Larsson LG, Holmstrom B, et al. Low-dose bupivacaine plus fentanyl for spinal anaesthesia during ambulatory inguinal herniorrhaphy: a comparison between $6 \mathrm{mg}$ and $7.5 \mathrm{mg}$ of bupivacaine. Acta Anaesthesiol Scand. 2003 Jan; 47(1):13-19.

[19]. Misirlioglu K, Sivrikaya GU, Hanci A, Yalcinkaya A, . Intrathecal low-dose levobupivacaine and bupivacaine combined with fentanyl in a randomised controlled study for caesarean section: blockade characteristics, maternal and neonatal effects, Hippokratia 2013; 17(3): 262-267.

[20]. Atalla MM, Shorrab AA, Abdel Mageed YM, Demian AD, . Low-dose bupivacaine spinal anaesthesia for percutaneous nephrolithotomy: the suitability and impact of adding intrathecal fentanyl. Acta Anaesthesiol Scand. 2006 Aug; 50(7):798-803.

[21]. Goel S, Bhardwaj N, Grover VK Intrathecal fentanyl added to intrathecal bupivacaine for day case surgery: a randomised study. Eur J Anaesthesiol. 2003 Apr; 20(4):294-297.

[22]. Chopra G, Kumar S, . Comparative evaluation of neonates delivered by elective caesarean section under general anaesthesia and spinal anaesthesia with intrathecal opioid (fentanyl). IOSR-JDMS; 2014; 12(3): 48-54.

Table-1. Demographic profile of the three study groups

\begin{tabular}{|l|c|l|l|l|c|}
\hline \multirow{2}{*}{ Parameters } & \multicolumn{4}{|c|}{ Mean \pm SD } & \multirow{2}{*}{ P value } \\
\cline { 2 - 6 } & Group B (n=25) & Group BF1 (n=25) & Group BF2 (n=25) & Total $(\mathbf{n}=75)$ & .153 \\
\hline Age (years) & $28.92 \pm 5.40$ & $30.72 \pm 5.97$ & $27.36 \pm 6.72$ & $29.00 \pm 6.13$ & .055 \\
\hline Weight $($ Kg) & $66.04 \pm 11.47$ & $64.28 \pm 8.86$ & $59.12 \pm 10.48$ & $63.15 \pm 10.61$ & .198 \\
\hline Height $(\mathrm{cm})$ & $150.96 \pm 6.81$ & $152.08 \pm 5.26$ & $148.84 \pm 6.95$ & $150.63 \pm 6.44$ & \\
\hline
\end{tabular}

Table-2. Haemodynamic parameters of three study groups

\begin{tabular}{|c|c|c|c|c|c|c|c|c|c|}
\hline \multirow{2}{*}{$\begin{array}{c}\text { SBP } \\
(\mathrm{mmHg})\end{array}$} & \multicolumn{2}{|c|}{ Group B $(n=25)$} & \multicolumn{2}{|c|}{ Group BF1 $(n=25)$} & \multicolumn{2}{|c|}{ Group BF2 (n=25) } & \multicolumn{2}{|c|}{ Total $(n=75)$} & \multirow{2}{*}{$\begin{array}{c}\text { P- } \\
\text { value }\end{array}$} \\
\hline & $\mathbf{n}$ & Mean \pm SD & $\mathbf{n}$ & Mean \pm SD & $\mathbf{n}$ & Mean \pm SD & $\mathbf{n}$ & Mean \pm SD & \\
\hline 0 -min & 25 & $123.28 \pm 10.56$ & 25 & $126.36 \pm 17.78$ & 25 & $125.88 \pm 13.05$ & 75 & $128.51 \pm 15.05$ & .404 \\
\hline 2-min & 25 & $106.04 \pm 13.12$ & 25 & $118.00 \pm 17.62$ & 25 & $108.52 \pm 16.74$ & 75 & $110.85 \pm 16.56$ & .054 \\
\hline 4-min & 25 & $103.56 \pm 17.12$ & 25 & $115.72 \pm 17.22$ & 25 & $106.12 \pm 16.15$ & 75 & $108.47 \pm 17.42$ & .032 \\
\hline 6-min & 25 & $111.40 \pm 12.49$ & 25 & $115.96 \pm 17.58$ & 25 & $110.44 \pm 11.94$ & 75 & $112.60 \pm 14.25$ & .027 \\
\hline 8-min & 25 & $110.44 \pm 9.26$ & 25 & $118.92 \pm 17.84$ & 25 & $113.44 \pm 12.85$ & 75 & $114.27 \pm 14.04$ & .095 \\
\hline 10-min & 25 & $111.72 \pm 14.07$ & 25 & $117.12 \pm 17.78$ & 25 & $110.63 \pm 12.73$ & 75 & $113.19 \pm 15.11$ & .273 \\
\hline 15-min & 25 & $106.36 \pm 13.53$ & 25 & $111.48 \pm 13.65$ & 25 & $111.09 \pm 11.28$ & 75 & $109.60 \pm 12.94$ & .306 \\
\hline 20-min & 25 & $103.76 \pm 11.06$ & 25 & $111.60 \pm 13.28$ & 25 & $111.43 \pm 9.99$ & 75 & $108.86 \pm 11.99$ & .030 \\
\hline $25-\min$ & 25 & $104.92 \pm 12.32$ & 25 & $109.00 \pm 13.76$ & 25 & $110.96 \pm 9.94$ & 75 & $108.22 \pm 12.26$ & .219 \\
\hline 30-min & 25 & $105.21 \pm 9.57$ & 25 & $108.75 \pm 13.92$ & 25 & $109.73 \pm 9.09$ & 75 & $107.84 \pm 11.14$ & .350 \\
\hline 35-min & 24 & $107.71 \pm 10.06$ & 22 & $110.36 \pm 13.15$ & 20 & $109.65 \pm 11.13$ & 66 & $109.18 \pm 11.37$ & .720 \\
\hline 40-min & 19 & $107.74 \pm 9.90$ & 15 & $115.00 \pm 15.78$ & 14 & $115.00 \pm 9.92$ & 48 & $112.13 \pm 12.32$ & .136 \\
\hline 45-min & 12 & $106.67 \pm 10.84$ & 9 & $117.89 \pm 16.84$ & 12 & $117.58 \pm 10.22$ & 33 & $113.70 \pm 13.28$ & .067 \\
\hline 60-min & 6 & $108.00 \pm 8.07$ & 3 & $115.67 \pm 4.04$ & 5 & $119.40 \pm 9.09$ & 14 & $113.71 \pm 9.02$ & .095 \\
\hline $75-\min$ & 2 & $110.00 \pm 9.89$ & 2 & $119.00 \pm 8.48$ & 1 & $126.00 \pm 0$ & 5 & $116.80 \pm 9.44$ & .476 \\
\hline $\begin{array}{c}\text { DBP } \\
(\mathrm{mmHg})\end{array}$ & & Group B & & Group BF1 & & Group BF2 & & Total & $\begin{array}{c}\text { P- } \\
\text { value }\end{array}$ \\
\hline & n & Mean+SD & $\mathbf{n}$ & Mean士SD & $\mathbf{n}$ & Mean士SD & $\mathbf{n}$ & Mean士SD & \\
\hline 0 -min & 25 & $79.32 \pm 7.76$ & 25 & $82.00 \pm 13.87$ & 25 & $80.92 \pm 10.61$ & 75 & $82.08 \pm 11.25$ & .289 \\
\hline 2-min & 25 & $62.04 \pm 11.04$ & 25 & $76.32 \pm 15.46$ & 25 & $66.20 \pm 15.76$ & 75 & $68.19 \pm 15.30$ & .052 \\
\hline 4-min & 25 & $60.16 \pm 14.22$ & 25 & $70.96 \pm 14.39$ & 25 & $63.64 \pm 14.46$ & 75 & $64.92 \pm 14.87$ & .030 \\
\hline 6-min & 25 & $63.68 \pm 10.11$ & 25 & $69.60 \pm 14.20$ & 25 & $66.16 \pm 11.44$ & 75 & $66.48 \pm 12.12$ & .025 \\
\hline 8-min & 25 & $64.16 \pm 8.31$ & 25 & $70.00 \pm 12.60$ & 25 & $65.21 \pm 11.06$ & 75 & $66.47 \pm 10.95$ & .134 \\
\hline 10-min & 25 & $63.24 \pm 14.37$ & 25 & $68.28 \pm 12.82$ & 25 & $64.04 \pm 12.02$ & 75 & $65.22 \pm 13.15$ & .354 \\
\hline 15-min & 25 & $59.60 \pm 10.81$ & 25 & $66.04 \pm 11.04$ & 25 & $62.87 \pm 13.70$ & 75 & $62.84 \pm 12.00$ & .166 \\
\hline 20-min & 25 & $59.00 \pm 11.55$ & 25 & $62.64 \pm 12.57$ & 25 & $62.09 \pm 12.07$ & 75 & $61.22 \pm 12.01$ & .523 \\
\hline 25-min & 25 & $56.80 \pm 9.24$ & 25 & $62.36 \pm 17.76$ & 25 & $61.96 \pm 11.17$ & 75 & $60.33 \pm 13.35$ & .267 \\
\hline 30-min & 25 & $55.50 \pm 8.90$ & 25 & $62.29 \pm 17.25$ & 25 & $61.59 \pm 9.94$ & 75 & $59.74 \pm 12.86$ & .135 \\
\hline 35-min & 24 & $56.88 \pm 8.23$ & 22 & $64.82 \pm 18.42$ & 20 & $60.00 \pm 11.58$ & 66 & $60.47 \pm 13.56$ & .137 \\
\hline 40-min & 19 & $58.63 \pm 7.13$ & 16 & $65.50 \pm 13.05$ & 16 & $64.63 \pm 10.31$ & 51 & $62.67 \pm 10.55$ & .105 \\
\hline 45-min & 12 & $59.25 \pm 11.03$ & 9 & $70.67 \pm 13.49$ & 12 & $66.00 \pm 9.38$ & 33 & $64.82 \pm 11.80$ & .078 \\
\hline
\end{tabular}


Comparative Study Of Low Doses Of Intrathecal Bupivacaine Admixed With Fentanyl Citrate In

\begin{tabular}{|c|c|c|c|c|c|c|c|c|c|}
\hline 60-min & 6 & $60.83 \pm 9.10$ & 3 & $66.00 \pm 4.35$ & 5 & $72.20 \pm 6.94$ & 14 & $66.00 \pm 8.76$ & .091 \\
\hline 75-min & 2 & $62.50 \pm 4.95$ & 2 & $61.50 \pm 13.43$ & 1 & $74.00 \pm 0$ & 5 & $64.40 \pm 8.96$ & .638 \\
\hline \multirow{2}{*}{$\begin{array}{c}\text { MAP } \\
(\mathbf{m m H g})\end{array}$} & \multicolumn{2}{|r|}{ Group B } & \multicolumn{2}{|r|}{ Group BF1 } & \multicolumn{2}{|r|}{ Group BF2 } & \multicolumn{2}{|r|}{ Total } & P- \\
\hline & n & Mean \pm SD & $\mathbf{n}$ & Mean \pm SD & $\mathrm{n}$ & Mean \pm SD & n & Mean \pm SD & value \\
\hline 0 -min & 25 & $94.12 \pm 8.59$ & 25 & $100.08 \pm 15.03$ & 25 & $96.88 \pm 11.76$ & 75 & $97.64 \pm 12.32$ & .171 \\
\hline 2-min & 25 & $75.52 \pm 11.43$ & 25 & $88.38 \pm 17.14$ & 25 & $83.12 \pm 17.19$ & 75 & $82.26 \pm 16.15$ & .057 \\
\hline 4-min & 25 & $74.24 \pm 14.01$ & 25 & $87.72 \pm 17.69$ & 25 & $79.24 \pm 14.05$ & 75 & $80.40 \pm 16.14$ & .010 \\
\hline 6-min & 25 & $79.00 \pm 10.31$ & 25 & $86.24 \pm 12.88$ & 25 & $82.72 \pm 11.11$ & 75 & $82.65 \pm 11.71$ & .041 \\
\hline 8-min & 25 & $80.32 \pm 7.40$ & 25 & $87.04 \pm 15.17$ & 25 & $82.63 \pm 10.98$ & 75 & $83.34 \pm 11.82$ & .124 \\
\hline 10-min & 25 & $79.96 \pm 13.96$ & 25 & $84.76 \pm 14.38$ & 25 & $78.96 \pm 12.76$ & 75 & $81.29 \pm 13.79$ & .294 \\
\hline 15-min & 25 & $75.72 \pm 11.60$ & 25 & $81.48 \pm 12.07$ & 25 & $81.74 \pm 14.06$ & 75 & $79.59 \pm 12.72$ & 173 \\
\hline 20-min & 25 & $75.12 \pm 8.97$ & 25 & $79.44 \pm 13.01$ & 25 & $78.70 \pm 12.61$ & 75 & $77.73 \pm 11.64$ & .382 \\
\hline 25-min & 25 & $72.52 \pm 8.92$ & 25 & $76.56 \pm 15.38$ & 25 & $79.04 \pm 10.45$ & 75 & $75.96 \pm 12.08$ & .167 \\
\hline 30-min & 25 & $72.96 \pm 7.33$ & 25 & $76.79 \pm 14.27$ & 25 & $78.86 \pm 9.15$ & 75 & $76.13 \pm 10.83$ & .171 \\
\hline 35-min & 24 & $74.96 \pm 7.59$ & 22 & $79.64 \pm 15.11$ & 20 & $79.30 \pm 11.82$ & 66 & $77.83 \pm 11.82$ & .332 \\
\hline 40-min & 19 & $75.68 \pm 6.31$ & 14 & $84.07 \pm 13.22$ & 16 & $83.00 \pm 9.49$ & 49 & $80.47 \pm 10.26$ & .059 \\
\hline 45-min & 11 & $74.27 \pm 4.19$ & 8 & $87.38 \pm 15.25$ & 12 & $83.67 \pm 8.86$ & 31 & $81.29 \pm 10.91$ & .058 \\
\hline 60-min & 6 & $77.67 \pm 7.28$ & 3 & $81.00 \pm 9.64$ & 4 & $90.25 \pm 4.57$ & 143 & $82.31 \pm 8.66$ & .061 \\
\hline 75-min & 2 & $79.00 \pm 4.24$ & 2 & $83.00 \pm 7.07$ & 1 & $98.00 \pm 0$ & 5 & $84.40 \pm 8.87$ & .216 \\
\hline
\end{tabular}

Table-3. Time to onset of sensory block to reach T6 and peak sensory block level

\begin{tabular}{|c|c|c|c|c|c|c|}
\hline \multicolumn{2}{|l|}{ Parameters } & $\begin{array}{l}\text { Group B }(n=25) \\
\text { Mean } \pm \text { SD }\end{array}$ & $\begin{array}{l}\text { GroupBF1 }(n=25) \\
\text { Mean } \pm \text { SD }\end{array}$ & $\begin{array}{l}\text { Group BF2 }(n=25) \\
\text { Mean } \pm \text { SD }\end{array}$ & $\begin{array}{l}\text { Total }(n=75) \\
\text { Mean } \pm \text { SD }\end{array}$ & P value \\
\hline \multicolumn{2}{|c|}{$\begin{array}{l}\text { Time of sensory } \\
\text { blockade at Thoracic dermatome } \\
\text { level-6 }\end{array}$} & $323.04 \pm 81.22$ & $218.16 \pm 49.20$ & $357.83 \pm 119.35$ & $298.08 \pm 104.56$ & $<.001$ \\
\hline \multirow{6}{*}{$\begin{array}{l}\text { Peak sensory } \\
\text { block level }\end{array}$} & $\mathrm{T} 2$ & $1(4.0 \%)$ & $1(4.0 \%)$ & - & $2(2.7 \%)$ & \multirow{6}{*}{---} \\
\hline & T3 & $3(12.0 \%)$ & $1(4.0 \%)$ & - & $4(5.3 \%)$ & \\
\hline & $\mathrm{T} 4$ & $15(60.0 \%)$ & $13(52.0 \%)$ & $11(44.0 \%)$ & $39(52.0 \%)$ & \\
\hline & T5 & $5(20.0 \%)$ & $9(36.0 \%)$ & $13(52.0 \%)$ & $27(36.0 \%)$ & \\
\hline & T6 & $1(4.0 \%)$ & $1(4.0 \%)$ & $1(4.0 \%)$ & $3(4.0 \%)$ & \\
\hline & Total & $25(100.0 \%)$ & $25(100.0 \%)$ & $25(100.0 \%)$ & $75(100.0 \%)$ & \\
\hline
\end{tabular}

Table-4. Duration of analgesia and APGAR score in the three study groups.

\begin{tabular}{|c|c|c|c|c|c|c|c|c|c|}
\hline \multirow{2}{*}{ Parameters } & \multicolumn{2}{|c|}{ Gr B } & \multicolumn{2}{|r|}{ Gr BF1 } & \multicolumn{2}{|r|}{ Gr BF2 } & \multicolumn{2}{|r|}{ Total } & \multirow{2}{*}{$\begin{array}{c}P \\
\text { value }\end{array}$} \\
\hline & $\mathrm{n}$ & $($ mean \pm SD $)$ & $\mathrm{n}$ & $($ mean \pm SD $)$ & $\mathrm{n}$ & $($ mean $\pm S D)$ & $\mathrm{n}$ & $(\mathrm{mean} \pm \mathrm{SD})$ & \\
\hline $\begin{array}{ll}\begin{array}{l}\text { Duration } \\
\text { analgesia }\end{array} & \text { of } \\
\end{array}$ & 25 & $105.24 \pm 22.09$ & 25 & $116.72 \pm 18.80$ & 25 & $98.91 \pm 17.38$ & 75 & $107.18 \pm 20.67$ & .008 \\
\hline APGAR score & 25 & $8.24 \pm .77$ & 25 & $8.32 \pm .74$ & 25 & $8.28 \pm .79$ & 75 & $8.28 \pm .76$ & .935 \\
\hline
\end{tabular}

Table-5. Comparison of analgesic supplementation and analgesic quality in 3 study groups.

\begin{tabular}{|l|l|l|l|l|}
\hline Parameters & Group B & Group BF1 & Group BF2 & Total \\
\hline Analgesic Supplement & $(\mathrm{n}=25)$ & $(\mathrm{n}=25)$ & $(\mathrm{n}=25)$ & $(\mathrm{n}=75)$ \\
\hline None & $25(100.0 \%)$ & $24(96.0 \%)$ & $20(80.0 \%)$ & $69(92.0 \%)$ \\
\hline Ketamine & - & - & $3(12.0 \%)$ & $3(4.0 \%)$ \\
\hline Pentazocin & - & $1(4.0 \%)$ & $2(8.0 \%)$ & $3(4.0 \%)$ \\
\hline Total & $25(100.0 \%)$ & $25(100.0 \%)$ & $25(100.0 \%)$ & $75(100.0 \%)$ \\
\hline Analgesic Quality & $(\mathrm{n}=25)$ & $(\mathrm{n}=25)$ & $(\mathrm{n}=25)$ & $(\mathrm{n}=25)$ \\
\hline Excellent & $16(64.0 \%)$ & $19(76.0 \%)$ & $11(44.0 \%)$ & $46(61.3 \%)$ \\
\hline Good & $6(24.0 \%)$ & $5(20.0 \%)$ & $6(24.0 \%)$ & $17(22.7 \%)$ \\
\hline Poor & $1(4.0 \%)$ & - & $6(24.0 \%)$ & $7(9.3 \%)$ \\
\hline Fair & $2(8.0 \%)$ & $1(4.0 \%)$ & $2(8.0 \%)$ & $5(6.1 \%)$ \\
\hline Total & $25(100.0 \%)$ & $25(100.0 \%)$ & $25(100.0 \%)$ & $75(100.0 \%)$ \\
\hline
\end{tabular}

Figure-1: Heart rate at different stages among the three study groups

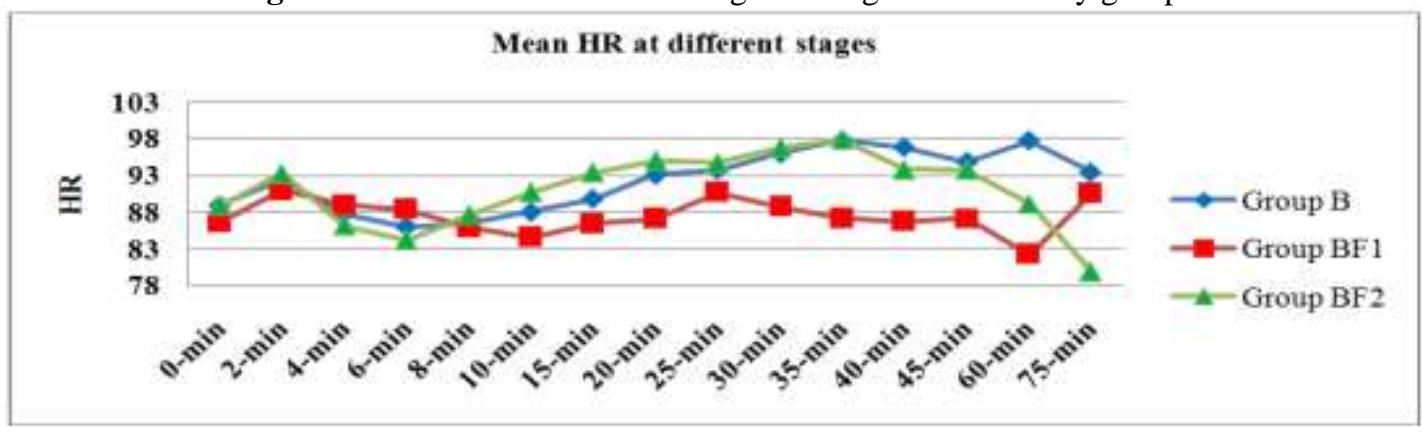

